\title{
DNA ANALYSIS OF DUCHENNE AND BECKER MUSCULAR DYSTROPHY USING pERT87 GENOMIC PROBES AND DYSTROPHIN cDNA PROBES
}

-Establishing the Optimum Strategy for Carrier Diagnosis in the Japanese Population-

Tsuneyuki UbagaI ${ }^{1}$ and Susumu Katayama ${ }^{2}$

${ }^{1}$ Department of Microbiology and ${ }^{2}$ the First Department of Obstetrics and Gynecology, Toho University, School of Medicine, Ohta-ku, Tokyo 143, Japan

Summary DNA analysis was performed on 19 unrelated Duchenne muscular dystrophy (DMD) families and one Becker muscular dystrophy (BMD) family in Japan to determine their carrier status. The intragenic genomic probe pERT87 with its subclones $87-1,87-8$, and $87-15$ were used together with five cDNA probes from the $5^{\prime}$ end of the dystrophin gene. The tests with both a high polymorphism information content (P.I.C.) and a high observed P.I.C. were most effective, i.e., pERT87-1/XmnI, pERT87-15/ XmnI, pERT87-8/TaqI, and pERT87-8/BstXI. These test combinations were useful in the Japanese population but pERT87-15/TaqI was not, although it was effective in Caucasians. Two additional test combinations of pERT87-1/MspI and pERT87-15/BamHI were highly useful in detecting restriction fragment length polymorphisms (RFLPs) when other tests were not informative. Carrier status could be determined in 18 out of 20 clients who were at risk for DMD/BMD carrier status from 20 families, similar to the rate of detection in Caucasians. The total detection rate of deletions was $74 \%$ with the five cDNA probes. Deletions were concentrated on two hot spots where $92 \%$ of all deletions were detected by only two probes, $1-2 \mathrm{a}$ and 8 . Deletions were detected in two males with DMD who had none of the eight RFLPs tested. Our results emphasize the usefulness of DNA analysis with pERT87 genomic probes and cDNA probes. In addition, an optimum strategy for carrier detection in Japanese DMD/BMD families was proposed.

Key Words DMD, RFLPs analysis, pERT87 probes, cDNA analysis, carrier diagnosis

Received, April 23, 1991; revised version received May 22, 1991, Accepted May 29, 1991.

Reprint request should be sent to Susumu Katayama. 


\section{INTRODUCTION}

Duchenne muscular dystrophy (DMD) is the most common lethal X-linked recessive disease with an incidence of approximately 1:3,500 live male births and there is no variation in its incidence between races. A boy affected with DMD usually exhibits signs before the age of six years, is confined to a wheelchair by age 12 , and dies by age 20 . Becker muscular dystrophy (BMD) is a less severe form of DMD, and develops signs in the thirties or later; its incidence is one-fifth to one-eighth of that of DMD. Both of these dystrophies have been elucidated to be caused by a common mutation consisting of deletion or duplication of exons within the dystrophin gene (Kingston et al., 1983; Kunkel et al., 1986; Monaco et $a l .$, 1988). Because $\mathrm{DMD} / \mathrm{BMD}$ are still incurable, determining the carrier status and affected fetuses would be very useful for at-risk mothers or relatives whose family members are affected with $\mathrm{DMD} / \mathrm{BMD}$ from the point of view of genetic counseling.

The diagnosis of DMD/BMD has long been made based on an elevated serum. creatine phosphokinase (CPK) level together with neurologic examination and pedigree analysis (Bullock et al., 1979). Carrier diagnosis has also relied on elevated CPK levels, but a more accurate and reliable diagnostic test for the carrier state has long been searched for, since CPK activity is elevated in only $70 \%$ of obligate carriers and thus is of limited utility (Moser, 1984).

On the basis of remarkable progress in the field of molecular biology in the 1970s, a method of diagnosing DMD/BMD using DNA probes was established in 1985 (Bakker et al., 1985). Kunkel et al. (1985) isolated pERT87 (DXS 164) DNA fragments from locus Xp21, which is deleted in males with DMD (Fig. 1). Probe pERT87 together with subclones 87-1, 87-8 (Monaco et al., 1985), and 87-15 (Bertelson et al., 1986) recognize six independent restriction fragment length polymorphisms (RFLPS) in human genomic DNA cleaved with four specific restriction enzymes, and is effective for carrier and prenatal diagnosis in Caucasians (Katayama et al., 1988). However, the usefulness of this probe may vary in the Japanese population, since RFLPs differ in their fragment sizes and allele frequencies depending on ethnic origin (Wainscoat et al., 1986).

Koenig et al. (1987) have cloned cDNA fragments of the DMD megagene spanning 2,000 $\mathrm{kb}$ at the $\mathrm{Xp} 21$ locus. Submicroscopic deletions were reportedly detected in about $60 \%$ of DMD/BMD patients using such cDNA probes (Koenig et al., 1987; Forrest et al., 1987; Read et al., 1988; Worton and Thompson, 1988; Darras et al., 1988; Liechti-Gallati et al., 1989). However, sufficient data has not been accumulated regarding RFLPs and deletion studies in Japanese DMD/BMD families (Akita et al., 1987; Sugino et al., 1989; Asano et al., 1990).

We have investigated the usefulness of three subclones of pERT87 (87-1, 87-8, and $87-15$ ) and then detection rate of the deletions related to DMD/BMD using 


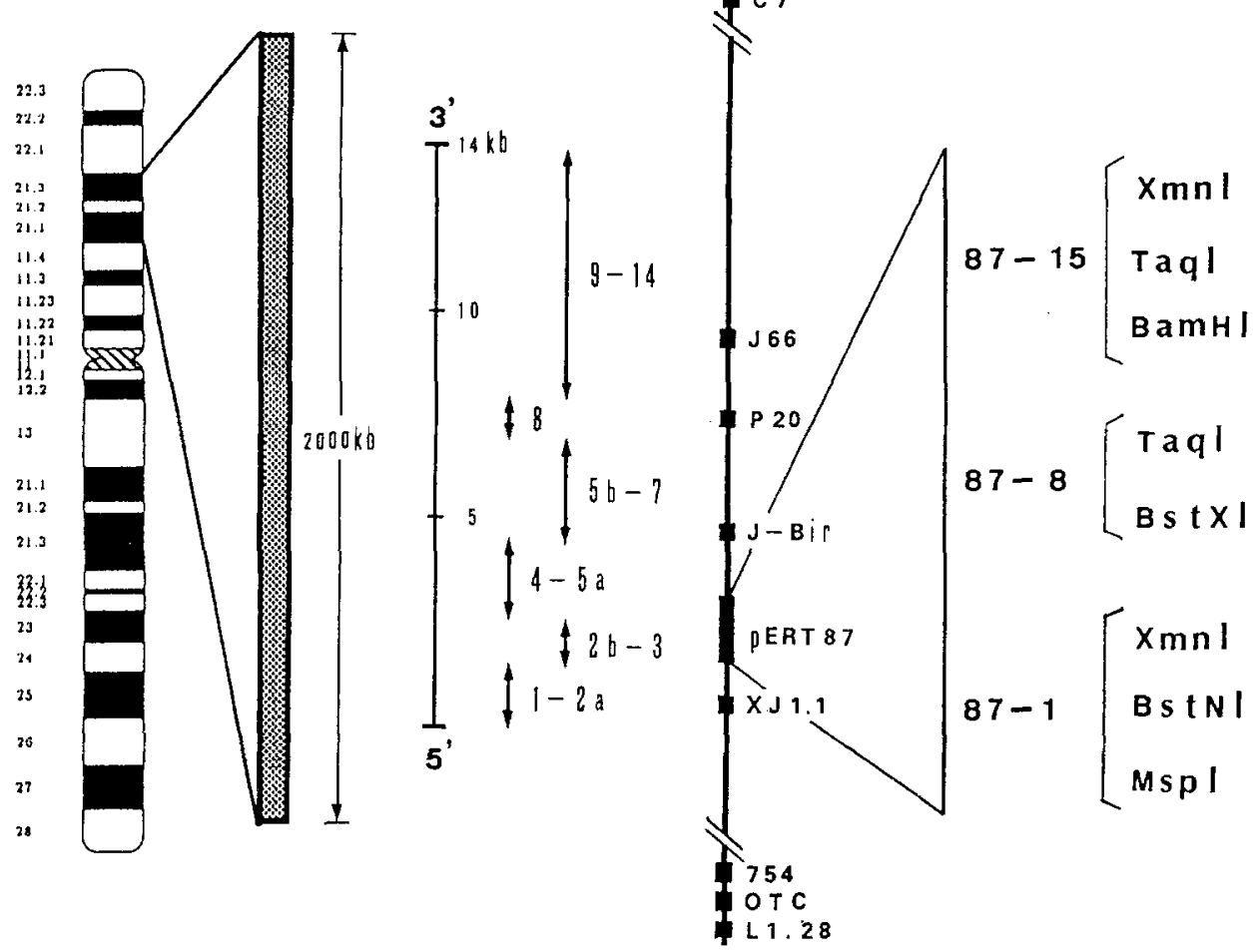
$\mathrm{X}$
A
B
C
D
$E$

Fig. 1. Genomic map of the DMD gene. Regional distribution of three loci detecting a total of eight RFLPs, and cDNA probes along the short arm of the $X$ chromosome. $\mathrm{X}, \mathrm{X}$ chromosome; $\mathrm{A}, \mathrm{DMD}$ gene; $\mathrm{B}, \mathrm{cDNA}(14 \mathrm{~kb})$ scale; $\mathrm{C}, \mathrm{cDNA}$ probes; D, genomic probes; $\mathrm{E}$, restriction enzyme.

cDNA probes. The aim of this study was to establish and present an optimum strategy for carrier and prenatal diagnosis of Japanese DMD/BMD individuals using genomic probes combined with cDNA probes.

\section{MATERIALS AND METHODS}

Families studied. One hundred and thirty-one members of 20 unrelated Japanese families with DMD/BMD were studied. Out of the 19 families with DMD, six had at least two affected males, and the other 13 had only one sporadic male with DMD in their pedigrees. The remaining one family had two males with BMD. In three families, the males affected by DMD had died before this DNA analysis was performed. Screening for deletions was done using dystrophin cDNA probes in a total of 19 males, 18 with DMD from 16 families (including one pair of brothers 
and one pair of cousins with DMD) and one with BMD. The diagnosis of DMD/ BMD was established by neurologists based on the family history, physical examination, electromyography, C.PK levels, and muscle biopsy results.

DNA analysis. DNA was extracted from peripheral white blood cells for carrier testing. DNA $(7 \mu \mathrm{g})$ was digested for $12 \mathrm{hr}$ with 5 units/ $/ \mathrm{g}$ DNA of the appropriate restriction endonucleases according to the manufacture's recommendations. The digests were then electrophoresed overnight on $1 \%$ agarose gels, and DNA was transferred from the gels to nylon filters (Hybond $\mathrm{N}+$; Amersham, U.K.) with $0.4 \mathrm{~N} \mathrm{NaOH}$ transfer buffer using a vacuum transfer system (Pharmacia LKB, Sweden). The filters were hybridized with the pERT87 probes or CDNA probes labeled by nick translation and $\left[\alpha^{2}{ }^{32} \mathrm{P}\right] \mathrm{dCTP}$ (Amersham). The filters were

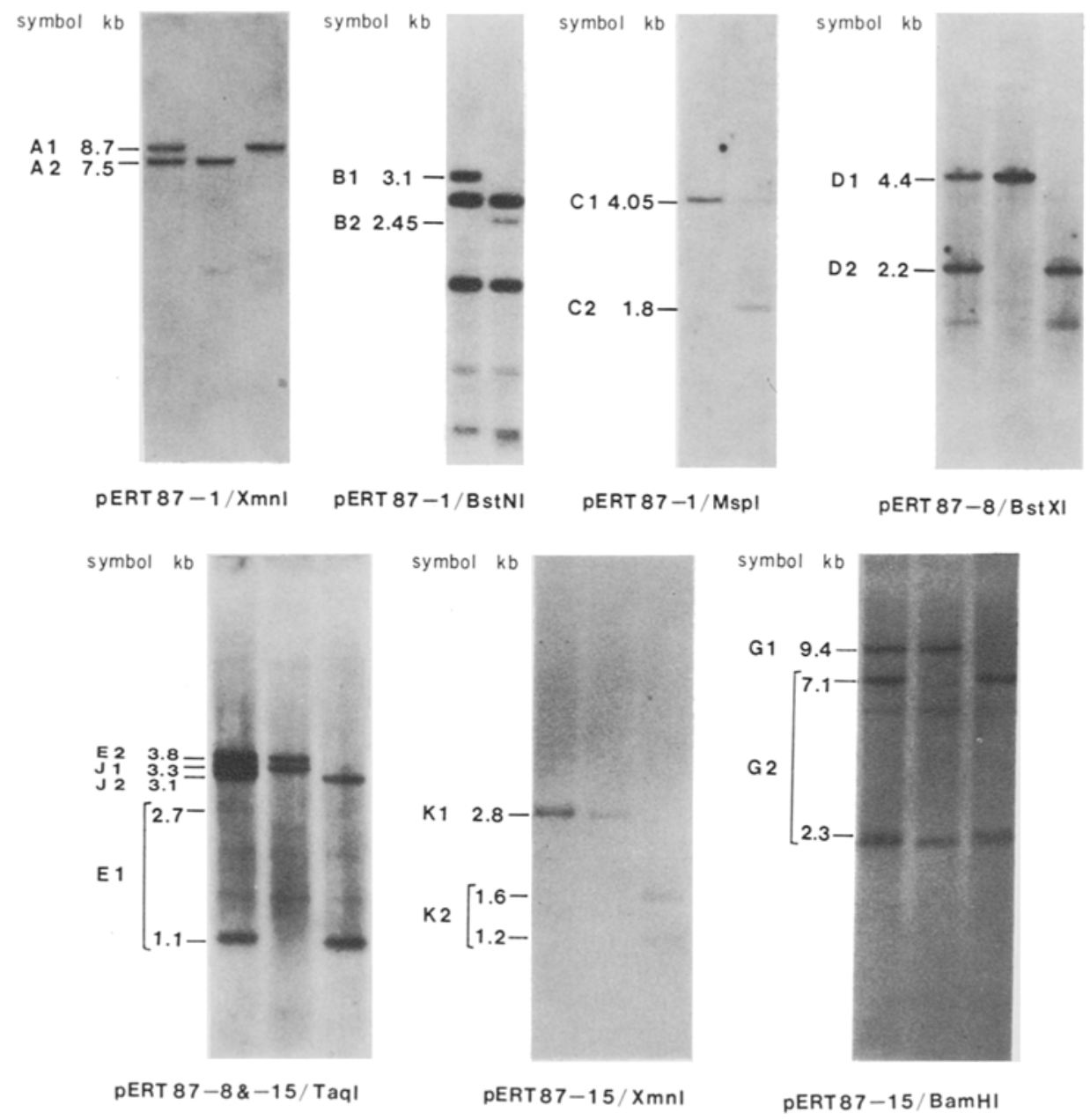

Fig. 2. Autoradiograms of RFLPs detected by pERT87 probes. 
washed in $2 \times \mathrm{SSC}$ and $1 \times$ Denhardt's solution at room temperature for $45 \mathrm{~min}$, then in $0.1 \times \mathrm{SSC}$ and $0.1 \%$ sodium dodecyl sulfate (SDS) with gentle shaking at $52^{\circ} \mathrm{C}$ for $90 \mathrm{~min}$, and finally four times in $0.1 \times \mathrm{SSC}$. Filters were exposed to Kodak $\mathrm{X}$-OMAT AR films between intensifying screens at $-80^{\circ} \mathrm{C}$ overnight and then developed (Fig. 2).

DNA probes. We used the three $\mathrm{X}$ chromosome-specific single copy sequences pERT87-1, pERT87-8, and pERT87-15, that have been mapped to band Xp21.2 for RFLPs analysis, while for detection of deletions the dystrophin cDNA probes $1-2 a, 2 b-3,4-5 a, 5 b-7$, and 8 from the $5^{\prime}$ end of the DMD/BMD gene (American Type Culture Collection) were used (Fig. 1).

\section{RESULTS}

\section{Frequency of polymorphisms}

Table 1 shows the allele frequencies and polymorphism information content

Table 1. Allele frequencies and polymorphism information contents of restriction fragment length polymorphisms for pERT87 DNA probes.

\begin{tabular}{|c|c|c|c|c|c|c|}
\hline Probes & $\begin{array}{l}\text { Restriction } \\
\text { enzyme }\end{array}$ & Symbol & $\begin{array}{c}\text { Allele } \\
\text { size (kb) }\end{array}$ & $\begin{array}{c}\text { Allele } \\
\text { frequency }\end{array}$ & \multicolumn{2}{|c|}{ P.I.C. $(\%)$} \\
\hline \multirow{6}{*}{ pERT87-1 } & $X m n I$ & A1 & 8.7 & 0.44 & & \\
\hline & & $\mathrm{A} 2$ & $\begin{array}{c}7.5 \\
(n=64)^{b}\end{array}$ & 0.56 & 49 & $(35)^{\mathrm{a}}$ \\
\hline & Bst NI & B1 & 3.1 & 0.45 & & \\
\hline & & B2 & $\begin{array}{c}2.45 \\
(\mathrm{n}=33)\end{array}$ & 0.55 & 50 & (24) \\
\hline & $M_{s p} \mathrm{I}$ & $\mathrm{C} 1$ & 4.05 & 0.86 & & \\
\hline & & $\mathrm{C} 2$ & $\begin{array}{c}1.8 \\
(\mathbf{n}=21)\end{array}$ & 0.14 & 24 & (20) \\
\hline \multirow[t]{4}{*}{ pERT 87-8 } & TaqI & E1 & $2.7 / 1.1$ & 0.33 & & \\
\hline & & E2 & $\begin{array}{c}3.8 \\
(\mathrm{n}=51)\end{array}$ & 0.67 & 44 & (45) \\
\hline & Bst XI & D1 & 4.4 & 0.29 & & \\
\hline & & $\mathrm{D} 2$ & $\begin{array}{c}2.2 \\
(\mathrm{n}=49)\end{array}$ & 0.71 & 41 & (40) \\
\hline \multirow[t]{7}{*}{ pERT87-15 } & $X m n I$ & K1 & 2.8 & 0.54 & & \\
\hline & & $\mathrm{K} 2$ & $\begin{array}{c}1.6 / 1.2 \\
(\mathrm{n}=46)\end{array}$ & 0.46 & 50 & (35) \\
\hline & $\operatorname{Taq} \mathbf{I}$ & $\mathrm{J} 1$ & 3.3 & 0.71 & & \\
\hline & & $\mathrm{J}_{2}$ & $\begin{array}{c}3.1 \\
(n=66)\end{array}$ & 0.29 & 41 & ( 7) \\
\hline & BamHI & GI & 9.4 & 0.22 & & \\
\hline & & $\mathrm{G} 2$ & $\begin{array}{r}7.1 / 2.3 \\
(\mathrm{n}=23)\end{array}$ & 0.78 & 34 & (20) \\
\hline & & & Total & & 99 & \\
\hline
\end{tabular}

a Values in parentheses represent the proportion of heterozygous females relative to total females examined, i.e., observed P.I.C. b Values in parentheses represent number of independent chromosomes counted in individuals related only by marriage but not genetically. 
(P.I.C.) of the three probes at the pERT87 (DXS164) locus. When pERT87-1 was used as a probe, the P.I.C. calculated from the allele frequency was $49 \%$ for the enzyme $X m n \mathrm{I}, 50 \%$ for $B s t \mathrm{NI}$, and $24 \%$ for $M s p \mathrm{I}$. When pERT87-8 was used, the P.I.C. was $44 \%$ for TaqI and $41 \%$ for Bst XI. The P.I.C. was $50 \%$ for $X m n I, 41 \%$ for $T a q \mathrm{I}$, and $34 \%$ for BamHI with the probe pERT87-15. When the four enzymes XmnI, Bst NI, TaqI, and BstXI were combined, the total P.I.C. was $98 \%$. This was raised to $99 \%$ by adding two more enzymes (MspI and BamHI).

The observed P.I.C. was as high as $35 \%$ when testing pERT87-1/XmnI. For pERT $87-8$, it was $45 \%$ with TaqI and $40 \%$ with BstXI. When XmnI was used, it was $35 \%$ for pERT87-15, followed by pERT87-1/MspI and pERT87-15/BamHI (both $20 \%$ ). The test of pERT87-15/TaqI showed the lowest P.I.C. of $7 \%$.

\section{Diagnostic applicability}

Table 2 shows the diagnostic applicability of combinations of the pERT87 subclones and six restriction enzymes in the 59 Japanese females examined. RFLPs were detected in $73 \%$ of all the females examined. They were detected in $39 \%$ when pERT87-1 was used with $X m n I$ and/or $M s p I$, in 50\% when pERT87-8 was used with TaqI and/or BstXI, and in 37\% when pERT87-15 was used with $X m n I$ and/or BamHI, with all combinations giving high detection rates. The combination of $X m n I / p E R T 87-8$ and -15 gave a $51 \%$ incidence of high RFLPs, although TaqI/

Table 2. Diagnostic applicability of combinations of pERT87 subclones and restriction enzymes for DMD/BMD diagnosis.

\begin{tabular}{|c|c|c|c|}
\hline \multirow{2}{*}{ Probes } & \multirow{2}{*}{ Restriction enzyme } & \multicolumn{2}{|c|}{ Applicability $(\%)$} \\
\hline & & P.I.C. & Observed P.I.C. \\
\hline \multirow[t]{4}{*}{ pERT87-1 } & $X m n \mathrm{I}$ and/or Bst $\mathrm{NI}$ & 74 & $37(19 / 51)^{\mathrm{a}}$ \\
\hline & $X m n \mathrm{I}$ and/or $M s p \mathrm{I}$ & 62 & $39(20 / 51)$ \\
\hline & $B s t \mathrm{NI}$ and/or $M s p \mathrm{I}$ & 62 & $29(9 / 31)$ \\
\hline & $X m n \mathrm{I}, B s t \mathrm{NI}$ and/or $M s p \mathrm{I}$ & 81 & $39(20 / 51)$ \\
\hline pERT87-8 & TaqI and/or Bst XI & 67 & $50(23 / 46)$ \\
\hline \multirow[t]{4}{*}{ pERT $87-15$} & $X m n \mathrm{I}$ and/or $T a q \mathrm{I}$ & 70 & $32(18 / 56)$ \\
\hline & $X m n I$ and/or BamHI & 67 & $37(15 / 41)$ \\
\hline & TaqI and/or BamHI & 61 & $15(8 / 53)$ \\
\hline & $X m n I, T a q \mathrm{I}$ and/or BamHI & 81 & $34(19 / 56)$ \\
\hline pERT87-1 and -15 & $X m n \mathrm{I}$ & 75 & $51(28 / 55)$ \\
\hline pERT87-8 and -15 & $\operatorname{Taq} \mathbf{I}$ & 67 & $32(19 / 59)$ \\
\hline All & $\begin{array}{l}X m n \mathrm{I}, B s t \mathrm{NI}, M s p \mathrm{I}, T a q \mathrm{I}, B s t \mathrm{XI} \\
\text { and/or BamHI }\end{array}$ & 99 & $73(43 / 59)$ \\
\hline
\end{tabular}

a Values in parentheses are the number of informative females relative to total females. 
pERT $87-8$ and -15 gave a $32 \%$ incidence of low RFLPs. When all three probes and all six restriction enzymes were used, the incidence of RFLPs was $99 \%$ for P.I.C. and $73 \%$ for observed P.I.C.

Result of carrier diagnosis by RFLPs analysis

Practical diagnosis of carrier status was possible in $90 \%$ of the individuals tested, i.e., carrier status were determined in 18 out of 20 members from 20 families. Table 3 shows the results. Deletions were not detected by the pERT 87 probes in any of the individuals examined.

\section{Result of detection of deletions with $c D N A$ probes}

Table 4 shows the result of detection of deletions when dystrophin cDNA probes were used in the 19 males with DMD/BMD from 17 families. Figure 3 shows an autoradiogram of the results obtained with cDNA probe 8 . The detection rate of deletions was $11,5,42$, and $58 \%$ with cDNA probes $1-2 \mathrm{a}, 2 \mathrm{~b}-3,5 \mathrm{~b}-7$, and 8 , respectively. Probe $4-5 \mathrm{a}$ did not detect any deletions. The total detection rate of deletions was $74 \%$ with the five cDNA probes. Of the 19 patients, $37 \%$ had deletions spanning the regions detected by two consecutive cDNA probes ( $5 \mathrm{~b}-7$ and 8 ), although only $5 \%$ had a deletion detected by both 1-2a and $2 \mathrm{~b}-3$. Almost

Table 3. Result of carrier diagnosis by RFLPs analysis in 20 females from 20 unrelated families.

\begin{tabular}{clll}
\hline $\begin{array}{l}\text { Total no. of } \\
\text { families }\end{array}$ & $\begin{array}{l}\text { Total no. of } \\
\text { client females }\end{array}$ & $\begin{array}{l}\text { No. of informative } \\
\text { females }\end{array}$ & $\begin{array}{l}\text { No. of uninfor- } \\
\text { mative females }\end{array}$ \\
\hline 20 & $20(100 \%)$ & $18(90 \%)$ & $2(10 \%)$ \\
\hline
\end{tabular}

Table 4. Result of detection of deletions in the DMD/BMD patients with cDNA probes.

\begin{tabular}{cc}
\hline cDNA probes & Deletion detection rate $(\%)$ \\
\hline $1-2 \mathrm{a}$ & $11(2 / 19)^{\mathrm{a}}$ \\
$2 \mathrm{~b}-3$ & $5(1 / 19)$ \\
$1-2 \mathrm{a} \& 2 \mathrm{~b}-3$ & $5(1 / 19)$ \\
$4-5 \mathrm{a}$ & $0(0 / 19)$ \\
$5 \mathrm{~b}-7$ & $42(8 / 19)$ \\
8 & $58(11 / 19)$ \\
$5 \mathrm{~b}-7 \& 8$ & $37(7 / 19)$ \\
\hline Total & $74(14 / 19)$ \\
\hline
\end{tabular}

a Values in parentheses are the number of DMD/BMD with detected deletion relative to total DMD/BMD examined.

Vol. 36, No. 3, 1991 
all the deletions $(92 \%)$ could be detected with just the two probes 1-2a and 8 . Junctional fragments were detected in two males $(14 \%)$ with DMD using cDNA probe 8. The distribution of deletions in the DMD/BMD patients is shown in Table 5.

\section{Examples of carrier diagnosis}

Figures 4 through 7 show practical examples of carrier diagnosis.
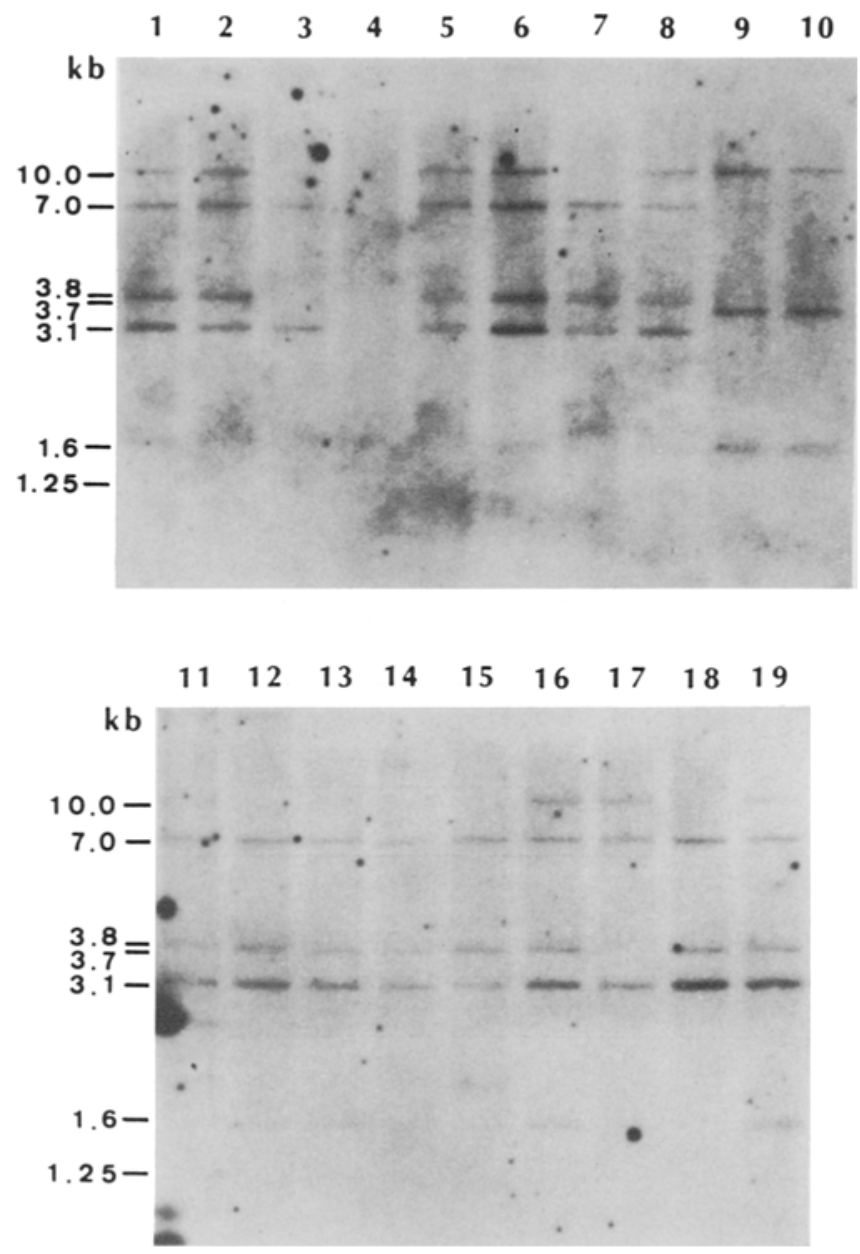

Fig. 3. Autoradiogram of HindIII fragments detected with cDNA probe 8 on 18 DMD patients (from no. 1 through no. 14 and no. 16 through no. 19) and one BMD patient (no. 15). In no. 3, $1.6,3.7,3.8$, and $10.0 \mathrm{~kb}$ fragments were deleted. All fragments were deleted in no. 4. No. $7,12,13$, and 15 deleted $10.0 \mathrm{~kb}$ fragments. No. 12 and 13 were brothers. Junctional fragments were detected in no. 9 and 10. A $1.6 \mathrm{~kb}$ fragment was deleted in no. 11. 1.6, 3.7, and $3.8 \mathrm{~kb}$ fragments were deleted in no. 17 . In no. $18,1.6$ and $10.0 \mathrm{~kb}$ fragments were deleted. 
Table 5. Distribution of deletions in the DMD/BMD patients relative to HindIII fragments detected with dystrophin cDNA probes.

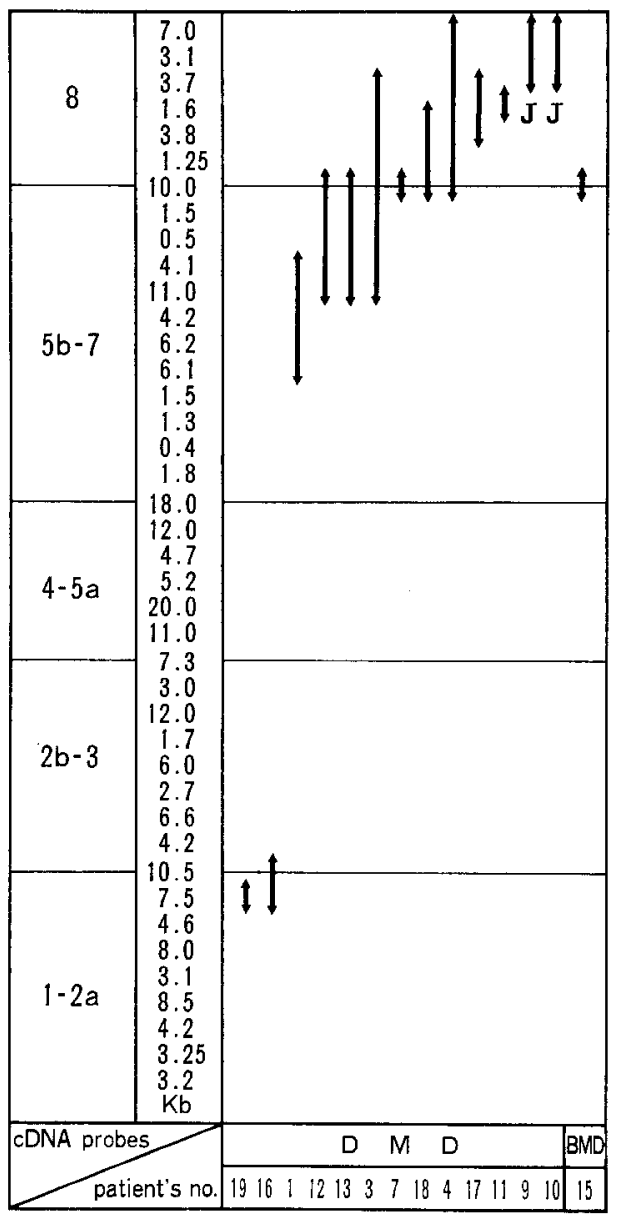

Figure 4 shows a family with three cases of inherited DMD. Both I-2 and II-3 were detected by using pERT87-15/XmnI. A male with DMD (II-5) inherited a $1.6 \mathrm{~kb}$ fragment (K2) from his mother (I-2). The same fragment was inherited by his sister (II-3), whose findings were consistent with carrier status. Her son (III-1) was affected with DMD because he inherited the same $1.6 \mathrm{~kb}$ fragment (K2). On the other hand, a healthy male (II-4) had a $2.8 \mathrm{~kb}$ fragment (K1) instead of the $1.6 \mathrm{~kb}$ fragment (K2). Junctional fragments were detected in II-5 and III-1 using cDNA probe 8 (Table 5 , patients no. 9 and 10 ).

Figure 5 shows a family with a sporadic case of DMD presumably caused by a spontaneous new mutation. Carrier diagnosis was possible with testing using pERT87-8/Bst XI. The father (I-1) was hemizygous for a $4.4 \mathrm{~kb}$ fragment (D1), and the mother (I-2) was homozygous for a $2.2 \mathrm{~kb}$ fragment (D2/D2). Their daugh- 


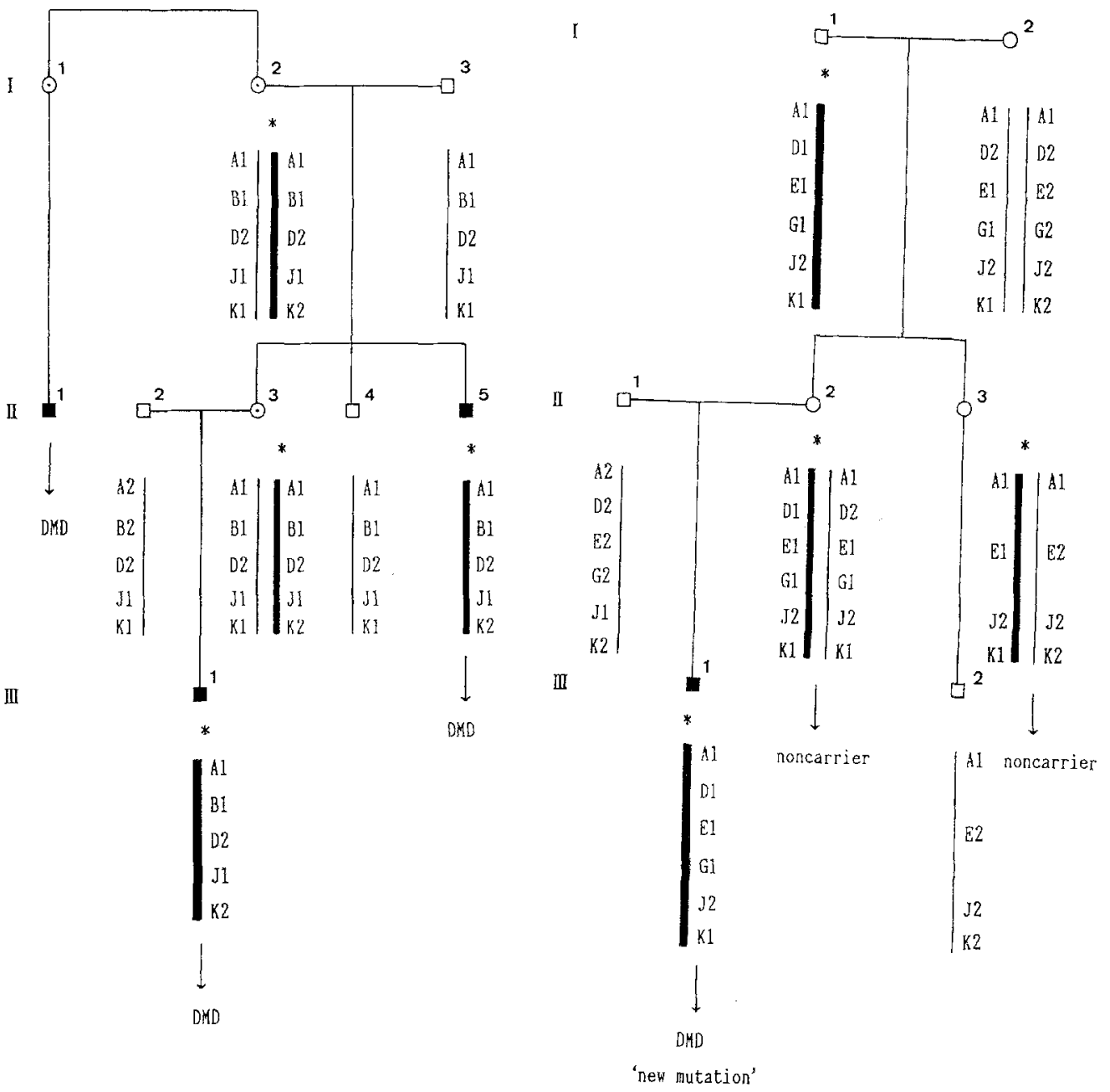

Fig. 4.

Fig. 5.

Fig. 4. A family with inherited DMD informative for pERT87-15. The asterisk indicates the $\mathrm{X}$ chromosome carrying the DMD locus. Junctional fragments were detected in II-5 and III-1 using cDNA probe 8. Squares represent males and circles represent females.

Fig. 5. A family with sporadic DMD caused by spontaneous new mutation demonstrated by pERT87-8. The X chromosome of DMD III- 1 is demonstrated to have come from its maternal grandfather I-1 and therefore DMD was caused by spontaneous new mutation. Deletions of DMD gene were detected in III-1 using cDNA probes 5b-7 and 8 . Squares represent males and circles represent females.

ter (II-2) was heterozygous for the $4.4 / 2.2 \mathrm{~kb}$ fragments (D1/D2). The X chromosome of the affected male (III-1) was demonstrated to have come from the maternal grandfather (I-1) who was healthy. This strongly suggested that the DMD in 


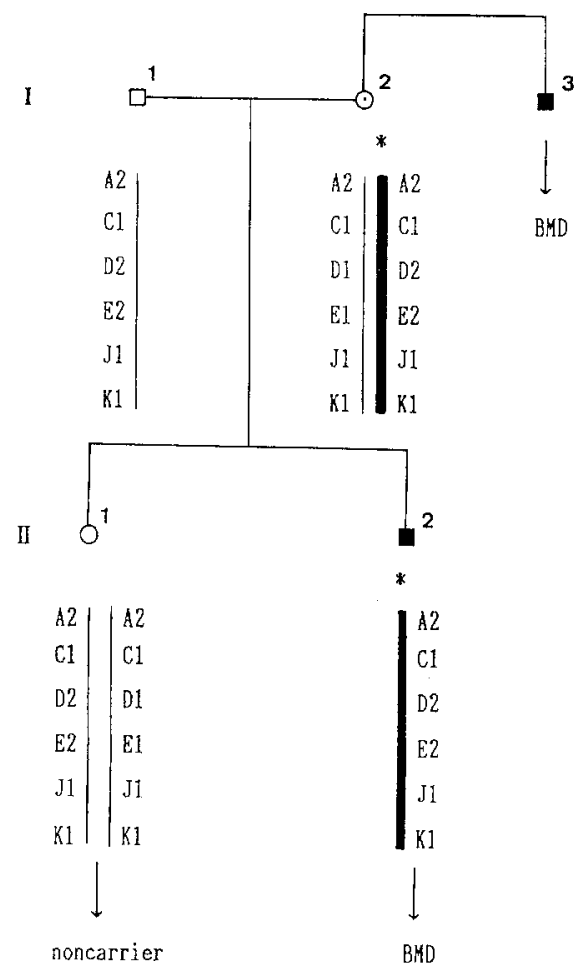

Fig. 6.

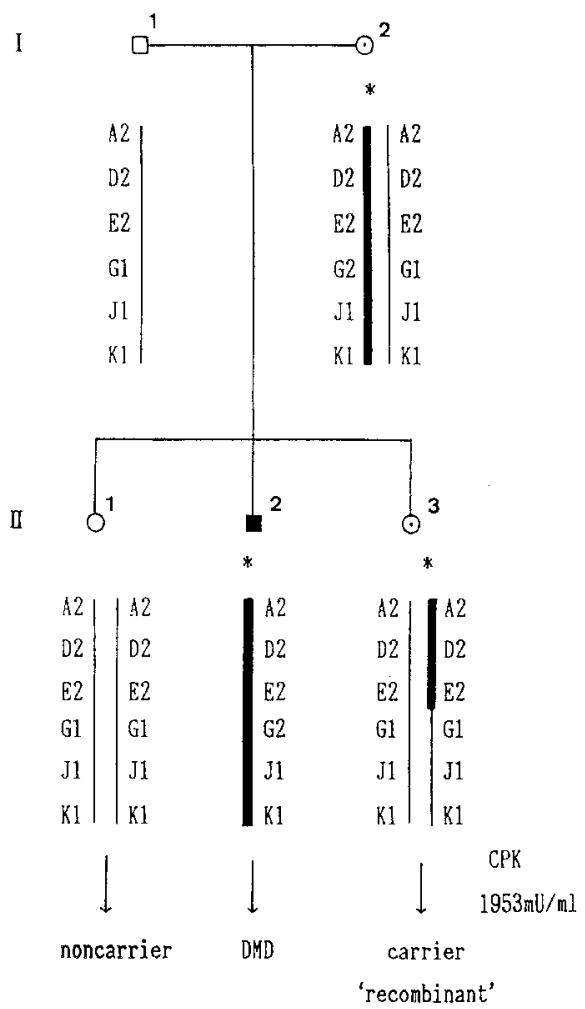

Fig. 7.

Fig. 6. A family with hereditary BMD informative for pERT87-8. The asterisk indicates the $\mathrm{X}$ chromosome carrying the BMD locus. The daughter II-1 is demonstrated to be a noncarrier. A deletion of BMD gene was detected in II-2 using cDNA probes $5 b-7$ and 8 . Squares represent males and circles represent females.

Fig. 7. A family with sporadic DMD informative for pERT87-15. The asterisk indicates the X chromosome carrying the DMD locus. II- 1 and II- 3 are demonstrated to have the same $X$ chromosomes which did not go to affected II-2, from their mother I-2. However, CPK level of II-3 was remarkably high and therefore II-3 was diagnosed to be carrier resulted from recombination event. A deletion of DMD gene was detected in II-2 using cDNA probe 1-2a. Squares represent males and circles represent females.

this case was caused by a new mutation. II-2 was diagnosed as a noncarrier. Deletions of the DMD gene were detected in III-1 using cDNA probes $5 b-7$ and 8 (Table 5, patient no. 18).

Figure 6 shows carrier diagnosis of a family with inherited BMD that was detected by pERT87-8/TaqI and pERT87-8/Bst XI. The mother (I-2) was heterozygous for $2.7 / 3.8 \mathrm{~kb}$ fragments (E1/E2) and 4.4/2.2 kb fragments (D1/D2). Although her son (II-2) affected with BMD inherited 3.8 and $2.2 \mathrm{~kb}$ fragments (E2/ D2), her daughter (II-1) inherited different fragments (2.7 and $4.4 \mathrm{~kb}, \mathrm{E} 1 / \mathrm{D} 1)$ demonstrating that she was a noncarrier. A deletion of the BMD gene was detected 
in $\mathrm{II}-2$ using cDNA probes $5 \mathrm{~b}-7$ and 8 (Table 5, patient no. 15).

Figure 7 shows a carrier caused by a recombination event in a family with sporadic DMD. In this case, RFLPs of the mother (I-2) were detected by testing with pERT87-15/BamHI. The mother (I-2) was heterozygous for $9.4 / 7.1 \mathrm{~kb}$ fragments $(\mathrm{G} 1 / \mathrm{G} 2)$ and the father (I-1) was hemizygous for $9.4 \mathrm{~kb}$ fragment (G1). Although the affected son (II-2) inherited a $7.1 \mathrm{~kb}$ fragment (G2), two daughters (II-1 and II-3) inherited a $9.4 \mathrm{~kb}$ fragment (G1), indicating that both had noncarrier status. However, the CPK level of daughter (II-3) was remarkably elevated (1953 $\mathrm{mU} / \mathrm{ml}$ ), so she was apparently a carrier resulting from recombination between the actual mutation and the probe pERT87-15. A deletion of the DMD gene was detected in II-2 using cDNA probe $1-2$ a (Table 5 , patient no. 19).

\section{DISCUSSION}

This DNA study exemplifies the usefulness of RFLPs analysis and deletion detection with pERT87 genomic probes and dystrophin cDNA probes in the carrier detection and prenatal diagnosis of Japanese DMD/BMD families. Allele frequencies of eight RFLPs were calculated first and then the polymorphism information content (P.I.C.) was investigated. Testing using pERT87-15/XmnI achieved the highest P.I.C. of $50 \%$, followed by pERT87-1/Bst NI, pERT87-1/XmnI, and pERT87-8/TaqI with 50,49 , and $44 \%$, respectively. Testing using pERT87-8/Bst XI and pERT87-15/TaqI had the same P.I.C. of $41 \%$, followed by pERT87-15/BamHI with $34 \%$. The use of pERT $87-1 /$ MspI achieved the lowest P.I.C. of $24 \%$. The total P.I.C. was $98 \%$ when six RFLPs were combined and increased to $99 \%$ with two additional RFLPs. The observed P.I.C. demonstrating the proportion of heterozygous females relatives to the number of total females examined was the highest using pERT87-8/TaqI (45\%), followed by pERT87-8/Bst XI, pERT87-1/ $X m n I$, pERT87-15/XmnI, and pERT87-1/Bst NI (40, 35, 35, and $24 \%$, respectively). Testing using pERT87-1/MspI and pERT87-15/BamHI achieved the same total P.I.C. of $20 \%$, whereas pERT87-15/TaqI had the lowest observed P.I.C. of $7 \%$. In practical carrier diagnosis of specific DMD/BMD families, the combinations which had not only a high P.I.C. but also a high observed P.I.C. were the most effective.

A comparison of our results to those obtained in Caucasians (Kunkel et al., 1985) shows that testing with combinations such as pERT87-1/XmnI, pERT87-15/ $X m n I$, pERT87-8/TaqI, and pERT87-8/Bst XI was also useful in the Japanese population, while pERT87-15/TagI which was effective in Caucasians was not useful. A recent article that reported the usefulness of pERT87-15/XmnI, pERT87-1/Bst NI, and pERT87-1/XmnI in the Japanese population (Sugino et al., 1989) was almost completely consistent with our results. Another report on the usefulness of four test combinations (Akita et al., 1987) was also consistent with our observations, except that pERT87-15/XmnI had a higher P.I.C. and pERT87-8/Bst XI had a lower P.I.C. 
in our study.

Two additional combinations of pERT87-1/MspI and pERT87-15/BamHI enabled us to detect RFLPs when other tests were not informative. They are highly useful since RFLPs could be detected in three out of five cases $(60 \%)$ which were not detected by the other six conventional tests combinations. Their P.I.C. and observed P.I.C. values, however, were both rather low. The reason might be that a small number of independent chromosomes was examined with these tests, so the P.I.C. and observed P.I.C. values could become higher with an increase of the number of individuals analyzed.

When carrier diagnosis was done on 20 individuals who were at risk as DMD/ BMD carriers from 20 unrelated families, carrier status could be determined in $90 \%$ $(18 / 20)$, consistent with the rate of $94 \%$ obtained previously in Caucasians (Katayama $e t$ al., 1988). This demonstrates the usefulness of RFLPs analysis with pERT87 genomic probes in carrier detection of DMD/BMD in the Japanese population.

The reliability of RFLPs analysis depends on the genetic distance between DNA probes and the actual gene mutation (Renwick, 1969). In the case of pERT87 probes, the probe is actually a part of the DMD/BMD gene. However the DMD/BMD gene is so large (estimated to span 2 million base pairs) that there is about a $2 \%$ recombination rate at each meiosis within the gene itself. Actually, a rate of about $5 \%$ for recombination events has been reported in Caucasian families (Kunkel et al., 1986). In the present study, we found one recombinant in 74 meiotic events out of 20 families analyzed (a $1.4 \%$ recombination rate that is consistent with the $2 \%$ theoretical value) (Fig. 7). The recombinant turned out to be a carrier based on the marked elevation of CPK activity, so we strongly suggest measurement of CPK activity in clients when making a diagnosis of carrier status.

One of the strong advantages of RFLPs analysis is that it may detect DMD/ BMD caused by a spontaneous new mutation (one-third of DMD/BMD cases) and separate it from that caused by an inherited mutation. In the present 20 families examined, seven out of 13 sporadic cases were considered to be caused by a spontaneous new mutation. This value was consistent with the theoretical one of $35 \%$ of all DMD/BMD cases and $54 \%$ of all sporadic cases (Haldane's rule). Another strong advantage of RFLPs analysis is that we can perform carrier diagnosis by assessing the $\mathrm{X}$ chromosomes of normal males even when DMD/BMD patients are not available in the family. We could make a carrier diagnosis in all three families where DMD cases were not available (17\% of the 18 families where carrier diagnosis was possible).

The total detection rate of deletion was $74 \%$ using five dystrophin cDNA probes of the $5^{\prime}$ end of the DMD/BMD gene. Deletions were detected in $72 \%(13 / 18)$ of the DMD patients and in the one BMD patient. This detection rate was rather higher than that of $25 \%$ in DMD and $50 \%$ in BMD for the Japanese population as a whole (Asano et al., 1990), resembling the high detection rate in Caucasians 


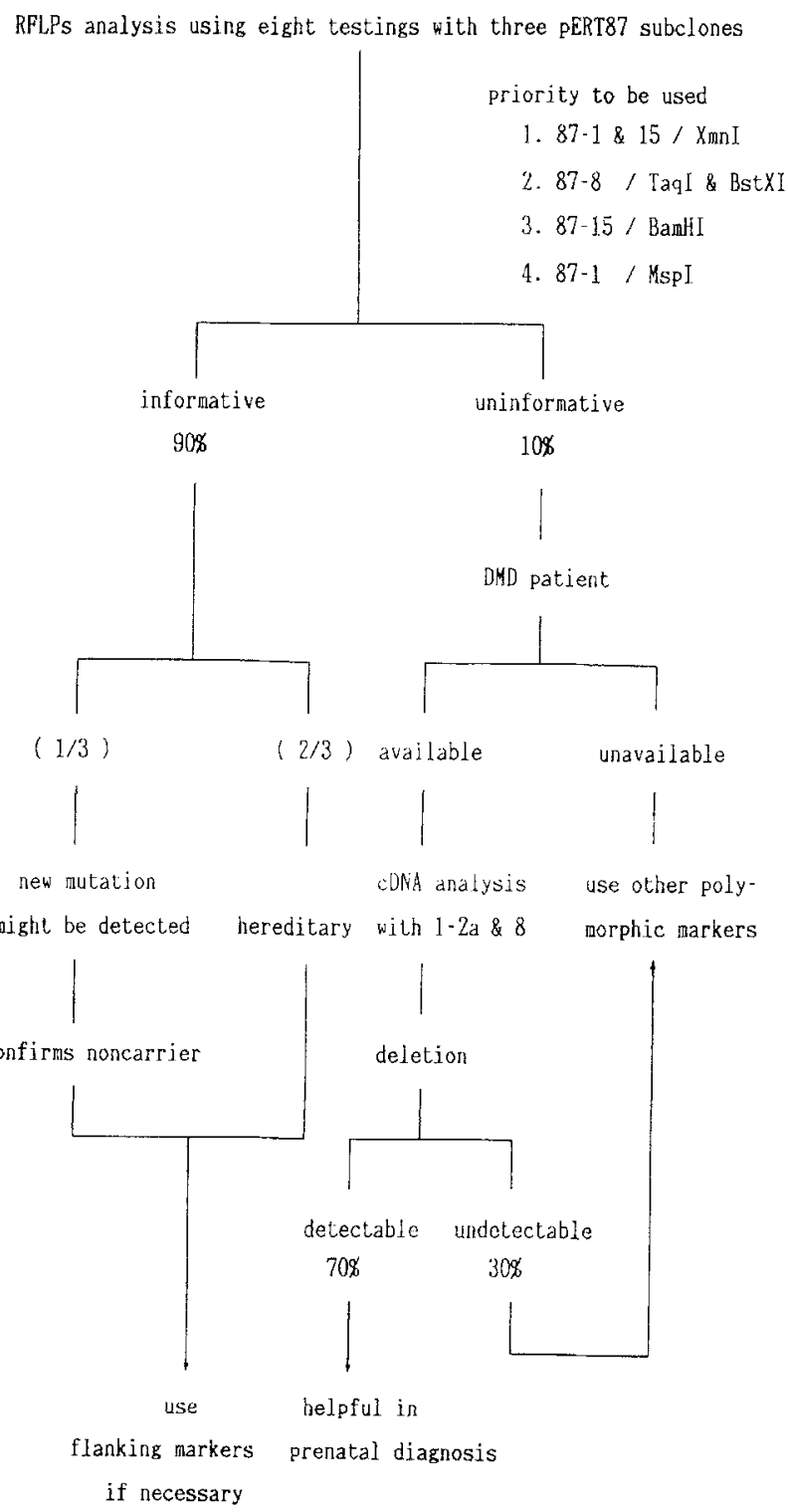

Fig. 8. Diagnostic algorithm of carrier detection of Japanese DMD.

(Koenig et al., 1987). The discrepancy might be explained by our small sample size-especially for BMD (one case). Deletions were concentrated on two hot spots where $92 \%$ of all deletions (12/13 deletions) were detected with two cDNA probes (1-2a and 8). Therefore, these two probes alone may be efficient enough to screen for deletions. Junctional fragments were also detected in two males with DMD (14\%) using cDNA probe 8. 
The detection of deletions with cDNA probes has some disadvantages in that it require living males with $\mathrm{DMD} / \mathrm{BMD}$, and in addition diagnosing carrier status is difficult because deciding the number of copies of a band on an autoradiograph is inaccurate and impossible in the presence of the normal chromosome. However, deletions were detected in two males with DMD from two families which were not detected by all eight RFLPs tested, one by both CDNA probes 5 b- 7 and 8 , and the other by probe 8 (Table 5 , patients no. 7 and 11). As the findings could be applied to prenatal diagnosis, cDNA analysis is worth doing when RFLPs testing is uninformative.

Based on the observations mentioned above, we propose the following as the most efficient and useful strategy for diagnosing carrier status in Japanese DMD/ BMD families. At first, eight RFLPs are tested with pERT87 genomic probes. The priority of the RFLPs tested should be in the order of 1) pERT87-1 and -15/ XmnI, 2) pERT87-8/TaqI and BstXI, 3) pERT87-15/BamHI, and 4) pERT87-1/ MspI. At this point, $90 \%$ of the clients will have shown at least one of the eight RFLPs. Additional use of some close flanking probes will rule out recombination and increase diagnostic accuracy. In the remaining 10\%, however, no RFLPs may be detectable. If males with DMD/BMD are available in this remaining $10 \%$ of the families, cDNA analysis can be used to detect deletions with the two cDNA probes $1-2 \mathrm{a}$ and 8 . In about $70 \%$ of $\mathrm{DMD} / \mathrm{BMD}$, deletions will be detected by this second test. These findings can be applied to prenatal diagnosis, although carrier status cannot be determined by the deletions detected. Finally, where deletions are not detected or males with DMD/BMD are unavailable, the use of other intragenic genomic probes like P20 or XJ1.1 or flanking markers like $\mathrm{C} 7$ or L.1.28 should be considered. This strategy is shown as a diagnostic algorithm in Fig. 8.

Acknowledgments We wish to thank Professor K. Yamaguchi of the Department of Microbiology for his critical review of the manuscript, Professor K. Momose and Associate Professor H. Kubo of the First Department of Obstetrics and Gynecology for providing an opportunity to do this work, and Professor H. Amano of the Department of Biochemistry and Associate Professor H. Shimatake of the Laboratory of Molecular Biology for their assistance.

This work was supported in part by a Grant-in-Aid for Scientific Research (C) from The Ministry of Education, Science and Culture of Japan, a Grant (2-A) from the National Center of Neurology and Psychiatry (NCNP) of The Ministry of Health and Welfare, Japan, a Grant for Advancement of Science in commemoration of Toho University's 60th Anniversary, and a Grant for Project Research from Toho University School of Medicine (No. 6324).

\section{REFERENCES}

Akita, Y., Obno, S., Goto, J., Nakano, I., Takatsu, M., Sugita, H. and Suzuki, K. 1987. Diagnosis of Duchenne and Becker muscular dystrophies by DNA polymorphism. Jpn. J. Human Genet. 32: 71-82.

Asano, J., Tomatsu, S., Sukekawa, K., Yamaguchi, S., Ikedo, Y., Minami, R., Iida, M., Nishimura, M., Nakagawa, M., Ohshiro, M. and Orii, T. 1990. Gene deletions in Japanese patients

Vol. 36, No. 3, 1991 
with Duchenne and Becker muscular dystrophy. Jpn. J. Human Genet. 35: 159-168.

Bakker, E., Goor, N., Wrogemann, K., Kunkel, L.M., Fenton, W.A., Majoor-Krakauer, D., Jahoda, M.G., Van Ommen, G.J.B., Hofker, M.H., Mandel, J.L., Davies, K.E., Willard, H.F., Sandkuyl, L., Essen, A.J.V., Sachs, E.S. and Pearson, P.L. 1985. Prenatal diagnosis and carrier detection of Duchenne muscular dystrophy with closely linked RFLPs. Lancet 1: 655-658.

Bertelson, C.J., Bartley, J.A., Monaco, A.P., Colletti-Feener, C., Fischbeck, K. and Kunkel, L.M. 1986. Localization of Xp21 meiotic exchange points in Duchenne muscular dystrophy families. J. Med. Genet. 23: 531-537.

Bullock, D.G., McSweeney, F.M., Whitehead, T.P. and Edwards, J.H. 1979. Serum creatine kinase activity and carrier status for Duchenne muscular dystrophy. Lancet 2: 1370.

Darras, B.T., Blattner, P., Harper, J.F., Spiro, A.J., Alter, S. and Francke, U. 1988. Intragenic deletions in 21 Duchenne muscular dystrophy (DMD)/Becker muscular dystrophy (BMD) families studied with the dystrophin cDNA: location of breakpoints on HindIII and $B g I I I$ exon-containing fragment maps, mitotic origin of the mutations. Am. J. Hum. Genet. 43: 620-629.

Forrest, S.M., Cross, G.S., Speer, A., Gradner-Medwin, D., Burnas, J. and Davies, K.E. 1987. Preferential deletion of exons in Duchenne and Becker muscular dystrophies. Nature 329: 638-640.

Katayama, S., Montano, M., Slotonick, N., Lebo, R.V. and Golbus, M.S. 1988. Prenatal diagnosis and carrier detection of Duchenne muscular dystrophy by restriction fragment length polymorphism analysis with pERT87 deoxyribonucleic acid probes. Am. J. Obstet. Gynecol. 158: 548-555.

Kingston, H.M., Harper, P.S., Person, P.L., Davis, K.E., Williamson, R. and Page, D. $1983 . \quad$ Localization of the gene for Becker muscular dystrophy. Lancet 2: 1200.

Koenig, M., Hoffmann, E.P., Bertelson, C.J., Monaco, A.P., Feener, C. and Kunkel, L.M. 1987. Complete cloning of the Duchenne muscular dystrophy (DMD) cDNA and preliminary genomic organization of the DMD gene in normal and affected individuals. Cell 50: 509 517 .

Kunkel, L.M., Monaco, A.P., Middlesworth, W., Ochs, H.D. and Latt, S.A. 1985 . Specific cloning of DNA fragments absent from the DNA of a male patient with an X chromosome deletion. Proc, Natl. Acad. Sci. U.S.A. 82: 4778-4782.

Kunkel, L.M. and co-authors. 1986. Analysis of deletions in DNA from patients with Becker and Duchenne muscular dystrophy. Nature 322: 73-77.

Liechti-Gallati, S., Koenig, M., Kunkel, L.M., Frey, D., Boltshauser, E., Schneider, V., Braga, S. and Moser, H. 1989. Molecular deletion patterns in Duchenne and Becker muscular dystrophy. Hum. Genet. 81: 343-348.

Monaco, A.P., Bertelson, C.J., Middlesworth, W., Colletti, C.-A., Aldridge, J., Fishbeck, K.H., Bartlett, R., Pericak-Vance, M.A., Roses, A.D. and Kunkel, L.M. 1985. Detection of deletions spanning the Duchenne muscular dystrophy locus using a tightly linked DNA segment. Nature 316: 842-845.

Monaco, A.P., Bertelson, C.J., Liechti-Gallati, S., Moser, H. and Kunkel, L.M. 1988. An explanation for the phenotypic differences between patients bearing partial deletions of the DMD locus. Genomics 2: 90-95.

Moser, H. 1984. Duchenne muscular dystrophy: Pathogenic aspects and genetic prevention. Hum. Genet. 66: 17-40.

Read, A.P., Mountford, R.C., Forrest, S.M., Kenwrick, S.J., Davies, K.E. and Harris, R. 1988. Patterns of exon deletions in Duchenne and Becker muscular dystrophy. Hum. Genet. 80: 152-156.

Renwick, J.H. 1969. Progress in mapping human autosomes. Br. Med. Bull. 25: 65-73.

Sugino, S., Fujisita, S., Kamimura, N., Matsumoto, T., Wapenaar, M.C., Deng, H.X., Shibuya, N., Miike, T. and Niikawa, N. 1989. Molecular-genetic study of Duchenne and Becker mus- 
cular dystrophies: Deletion analyses of 45 Japanese patients and segregation analyses in their families with RFLPs based on the data from normal Japanese females. Am. J. Med. Genet. 34: $555-561$.

Wainscoat, J.S., Hill, A.V.S., Boyce, A.L., Flint, J., Hernandez, M., Thein, S.L., Old, J.M., Lynch, J.R., Falusi, A.G., Weatherall, D.J. and Clegg, J.B. 1986. Evolutionary relationships of human populations from an analysis of nuclear DNA polymorphisms. Nature 319: 491-493.

Worton, R.G. and Thompson, M.W. 1988. Genetics of Duchenne muscular dystrophy. In Annual Review of Genetics, Cambell, A., Baker, B.S. and Herskowitz, I., eds. Vol. 22. Annual Reviews, Inc., Palo Alto, California, pp. 601-629. 